\title{
NOTE
}

\section{In vitro treatments for the theront stage of the ciliate protozoan Cryptocaryon irritans}

\author{
S. M. Picón-Camacho ${ }^{1}$, M. R. Ruiz de Ybáñez ${ }^{2}$, A. S. Holzer ${ }^{3}$, \\ M. Arizcun Arizcun ${ }^{4}$, P. Muñoz ${ }^{2, *}$ \\ ${ }^{1}$ Institute of Aquaculture, University of Stirling, Stirling FK9 4LA, UK \\ ${ }^{2}$ Department of Animal Health, Faculty of Veterinary Science, University of Murcia, 30100 Murcia, Spain \\ ${ }^{3}$ Cavanilles Institute of Evolutive Biology and Biodiversity, University of Valencia 22085, 46071 Valencia, Spain \\ ${ }^{4}$ Spanish Institute of Oceanography, Oceanographic Centre of Murcia, Planta de cultivos marinos, \\ 30860 Puerto de Mazarrón, Spain
}

\begin{abstract}
The ciliate protozoan Cryptocaryon irritans Brown, 1951, the 'marine white spot', causes one of the most important parasitic fish diseases, with extensive losses every year in mariculture and in the ornamental fish industry. In the present study, we explore the in vitro use of 8 different compounds against the theront (infective) stage of $C$. irritans; these compounds include extracts of natural products (epigallocatechin gallate (EGCG), L-DOPA, papain), peracetic acid-based compounds (Proxitane ${ }^{\circledR}$ 5:23 and 15\% peracetic acid, PAA), quinine-based compounds (quinacrine hydrochloride and chloroquine diphosphate) and hydrogen peroxide. All of these compounds had an effect on theront survival; however, only EGCG caused significant theront mortality when applied in doses $\geq 50 \mathrm{mg} \mathrm{l}^{-1}$ and over a period of $3 \mathrm{~h}$; papain caused a maximum theront mortality of $<50 \%$. We discuss the type of application and potential utility of the compounds tested as part of a management control strategy for $C$. irritans infections in marine aquaculture and the ornamental fish industry.
\end{abstract}

KEY WORDS: Marine white spot · Chemotherapy $\cdot$ Epigallocatechin gallate $\cdot$ Peracetic acid $\cdot$ Quinine Fish $\cdot$ Parasite

Resale or republication not permitted without written consent of the publisher

\section{INTRODUCTION}

Crytocaryon irritans Brown, 1951 is a marine holotrich protozoan, commonly known as 'marine white spot' or the 'marine Ich'; it causes what is considered to be one of the most devastating parasitic diseases in both mariculture and the ornamental fish industry (Wright \& Colorni 2002). High mortality levels are caused primarily by osmotic shock, when the parasite enters or exits the fish, as well as by secondary bacterial and fungal infections (Diggles \& Adlard 1997).

Cryptocaryon irritans is an obligate parasite with a direct life cycle that includes 4 stages. The trophont, i.e. the feeding stage (Stage 1) develops within the epidermis of the fish host and feeds on cellular material.
When the trophont reaches an appropriate size it leaves the host and enters Stage 2, the tomont. The tomont encysts and divides by asymmetric binary division, producing cells of Stage 3, the tomites. Tomites are released into the water column and differentiate into the infective cells of Stage 4, the theronts. The size and longevity of the theront is determined by several factors, such as temperature, salinity, strain of parasite and host species (Yoshinaga \& Dickerson 1994, Chu et al. 2001). Nonetheless, in most strains of the parasite the theront needs to find a host in $<24 \mathrm{~h}$ in order to complete its life-cycle, otherwise it dies (Colorni 1985).

The most effective treatment for controlling Cryptocaryon irritans, malachite green, was banned by the European Commission for use in fish destined for 
human consumption owing to its carcinogenicity (EC directive 90/676/EEC; article 14, regulation 2377/90/ EEC). Some other treatments for parasites have been tested with varying degrees of success (Colorni 1985, Hirazawa et al. 2001, 2003). In the current study we investigated the in-bath use of a wide range of compounds representing extracts of natural products, peracetic acid-based compounds, quinine-based compounds, and hydrogen peroxide, with the aim of eliminating the theront stage from the water column.

\section{MATERIALS AND METHODS}

Gilthead sea bream Sparus aurata L. (30 ind.; average weight $5 \mathrm{~g}$ ), naturally infected with Cryptocaryon irritans were maintained in a static 1201 PVC tank containing carbon-filtered seawater at 25 to $26^{\circ} \mathrm{C}$ with a salinity of 28 to 32 . Water temperature was maintained at $25^{\circ} \mathrm{C} \pm 1^{\circ} \mathrm{C}$ using a $100 \mathrm{~W}$ heater (Tetratec Aquarium heater); it was checked twice a day and adjusted if necessary. About $25 \%$ of the water was replaced twice a day. Uninfected sea bream (50 ind.; average weight $20 \mathrm{~g}$ ), which had not previously been exposed to C. irritans, were kept in a separate 1201 PVC static tank with the same conditions of salinity and temperature as the infected fish. When infected fish died as a result of $C$. irritans infection they were replaced with naïve individuals to maintain the infection. These replacements were carried out at intervals of $\sim 4$ to $7 \mathrm{~d}$.

Glass Petri dishes were placed on the bottom of the tank containing the infected fish. The Petri dishes were checked every $24 \mathrm{~h}$ under a stereomicroscope (Nikon, SMZ 800) for the presence of cysts. Petri dishes containing cysts were transferred to a clean tank containing carbon-filtered seawater held under the same conditions as the other tanks. After $6 \mathrm{~d}$ the theront stages were collected from the water and checked for motility under the microscope before being used in the in vitro trials.

A total of 50 Petri dishes (diameter $5 \mathrm{~cm}$ ) were set up, each with $2 \mathrm{ml}$ of the theront culture containing $\sim 250$ parasites and $2 \mathrm{ml}$ of 2 -fold concentrated chemicals for treatment. After the period of exposure (Tables 1 \& 2), the number of living vs. dead theronts was determined in $500 \mu \mathrm{l}$ of the experimental culture which was aliquoted into 40 small droplets and then observed under the stereomicroscope. Theronts were considered to be alive when they were actively motile; static ones were considered to be dead. All stock solutions, and the concentrations of each chemical tested, are detailed in Tables 1 \& 2. Each concentration was tested in triplicate against 4 untreated controls. Whenever a chemical had to be diluted in a solvent (i.e. dimethyl sulfoxide, DMSO, or glycerol) prior to use, 2 controls were tested in the corresponding concentration of solvent in addition to 2 controls containing only sea water.

The results are expressed as the percentage of theront mortality \pm standard error (Tables $1 \& 2$ ). The data were first transformed using the ArcSin Function and then analysed using 1-way ANOVA. When significant differences were found between the treatments, the multiple comparisons Tukey-Kramer test was conducted. Differences were considered significant at $\mathrm{p}<$ 0.05. All analyses were carried out using the software SPSS version 18 (IBM).

\section{RESULTS AND DISCUSSION}

The use of natural-based products for the treatment of pathogens has been demonstrated to have several advantages related to low toxicity and high efficacy. Polyphenolic compounds in green tea (Camellia sinensis L.) are known as catechins, one of the most important being epigallocatechin gallate (EGCG). These catechins are potent antioxidants with beneficial effects on human health (Williamson et al. 2006, Raza \& John 2008). EGCG has an important role in cell differentiation as it is able to inhibit the growth of malignant cells (Park \& Surh 2004). In fish ectoparasites, a crude extract of green tea (GTE) has been used, at low concentrations, against the flagellate Ichthyobodo necator Henneguy, 1883 in salmonids. These treatments reduced the number of parasites by $\sim 80 \%$ with no mortality in the treated groups. EGCG comprises $14 \%$ of GTE, and it was shown that an application of pure EGCG was able to reduce I. necator infections (Suzuki et al. 2006). Leiro et al. (2004) showed that in vitro exposure to $500 \mu \mathrm{M}$ of EGCG over $1 \mathrm{wk}$ reduced the population density of the ciliate Philasterides dicentrarchi Dragesco et al., 1995 by $93 \%$. In the present study, EGCG managed to kill all theronts when applied at 50,250 or $500 \mathrm{mg} \mathrm{l}^{-1}$ over a period of $3 \mathrm{~h}$, whereas its efficacy was considerably lower when application times were shorter and doses were lower (Table 1).

When EGCG was tested in vitro against the sporozoite stage of Plasmodium spp., the causative agent of malaria, it was found to reduce its motility. This reduction in motility is most likely due to the inactivation of proteins on the surface of the parasite. However, to kill the parasite efficiently it was necessary to increase the concentration of EGCG up to 8 times the concentrations needed to reduce motility (Hellmann et al. 2010). In the present study, EGCG might have had a similar effect on the motility of the theronts of Cryptocaryon irritans. It remains questionable whether the concentrations tested in our study managed to kill the theronts 
Table 1. Natural compounds (epigallocatechin gallate, L-DOPA and papain), stock solutions, solvent, concentrations tested, time of exposure and percentage of theront mortality \pm 1 SE of Cryptocaryon irritans Brown, 1951. DMSO: dimethyl sulfoxide; n: number of replicates; SW: carbon-filtered sea water; significant differences compared to the control groups: ${ }^{*} p<0.05,{ }^{* *} p \leq 0.001$

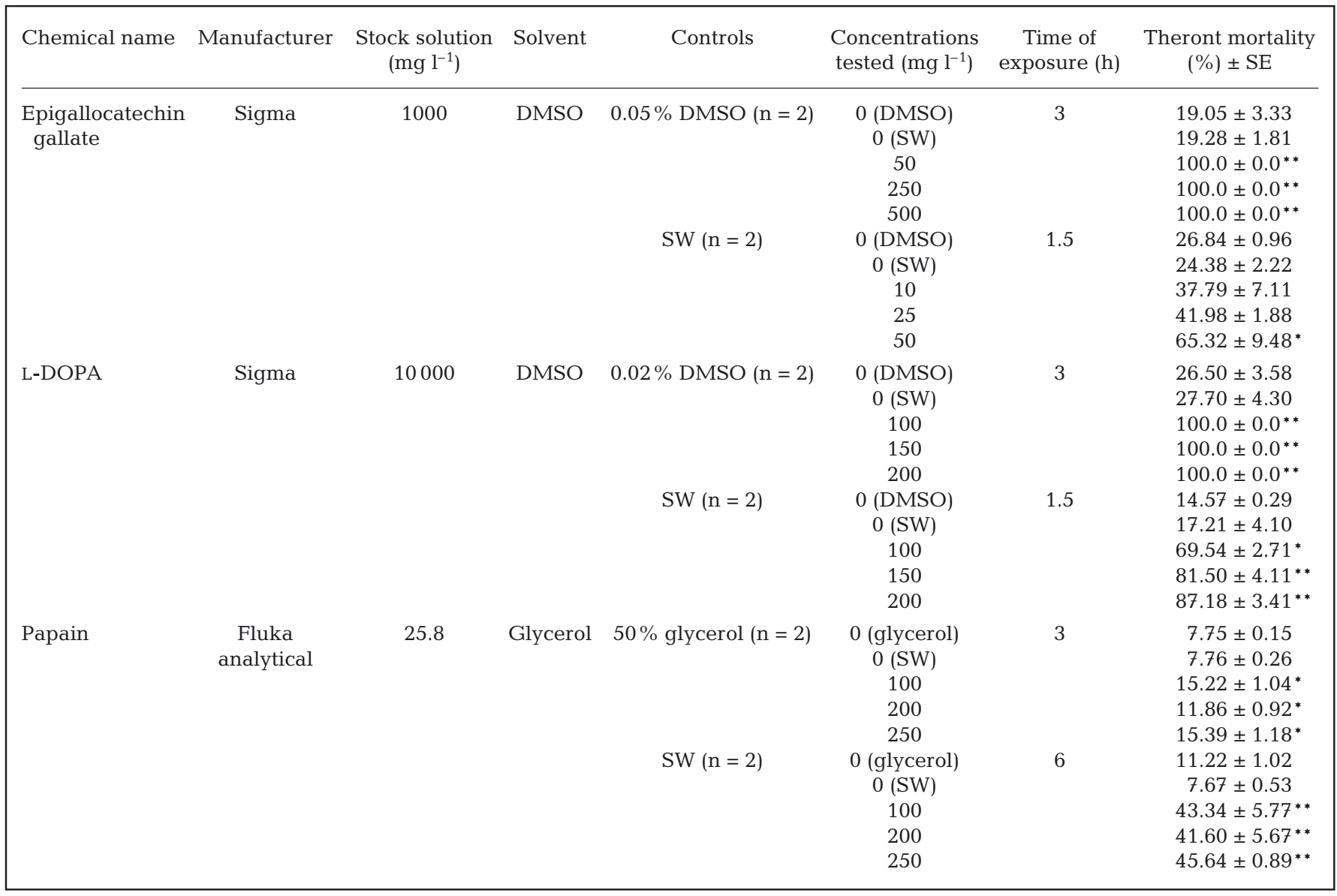

or whether they achieved only a reduction in their motility. However, the motility of the theront stage is crucial for finding and penetrating the skin of the host. Thus, a reduction in its motility will diminish its ability to infect successfully and, hence, diminish its ability to complete the life cycle. Some studies have demonstrated the low toxicity of certain polyphenols in mice and humans (García et al. 2003). It has therefore been hypothesized that these polyphenols would not be toxic to fish when used under in vivo conditions (Leiro et al. 2004). Suzuki et al (2006) studied the efficacy and safety of GTE in salmonids under hatchery conditions, but the concentrations used were much lower than the efficient concentration tested in the present study against $C$. irritants. Considering its high market price, and the concern regarding possible instability of polyphenols in seawater, the most worthwhile application of GTE would be to use it as an in-feed treatment. Nevertheless, the potential side effects of the in-feed application of polyphenols need to be taken into consideration, and further research is required.
L-DOPA (3,4-dihydroxy-L-phenylalanine) and papain are the active components of the traditional human medicinal plants Mucuna pruriens L. and Carica papaya L. respectively (Duke 1981, Tona et al. 1998). L-DOPA is used in humans as a therapeutic drug in Parkinson's disease as well as an insect killer (Duke 1981). It is a reactive oxygen species donor responsible for apoptosis (Ali et al 2010). Papain, also known as papaya proteinase I, is a cysteine protease belonging to a family of related proteins with a wide variety of activities, including endopeptidases, aminopeptidases, dipeptidyl peptidases, and enzymes which have both exopeptidase and endopeptidase activity. M. pruriens L. and C. papaya L. have been successfully tested in vitro and in vivo against the fish ciliate parasite Ichthyophthirius multifiliis (Ekanem et al. 2004). In the current study, L-DOPA had a lethal effect on the theronts of Cryptocaryon irritans with 100\% mortality after $3 \mathrm{~h}$ of exposure to 100, 150 and $200 \mathrm{mg}$ $\mathrm{l}^{-1}$. When the period of exposure was reduced to $1.5 \mathrm{~h}$, the highest doses, 150 and $200 \mathrm{mg} \mathrm{l}^{-1}$, proved effec- 
Table 2. Peracetic acid-based compounds (Proxitane ${ }^{\circledR}$ 5:23 and 15\% peracetic acid), quinine-based products (quinacrine hydrochloride and cloroquine diphosphate), hydrogen peroxide, stock solutions, solvent, concentrations tested, time of exposure and percentage of theront mortality \pm 1 SE of Cryptocaryon irritans Brown, 1951. $\mathrm{n}=$ number of replicates, $\mathrm{SW}=$ carbon-filtered sea water; ${ }^{*}$ significant differences $(p<0.05)$ compared to the control groups, ${ }^{* *}$ significant differences $(p \leq 0.001)$ compared to the control groups

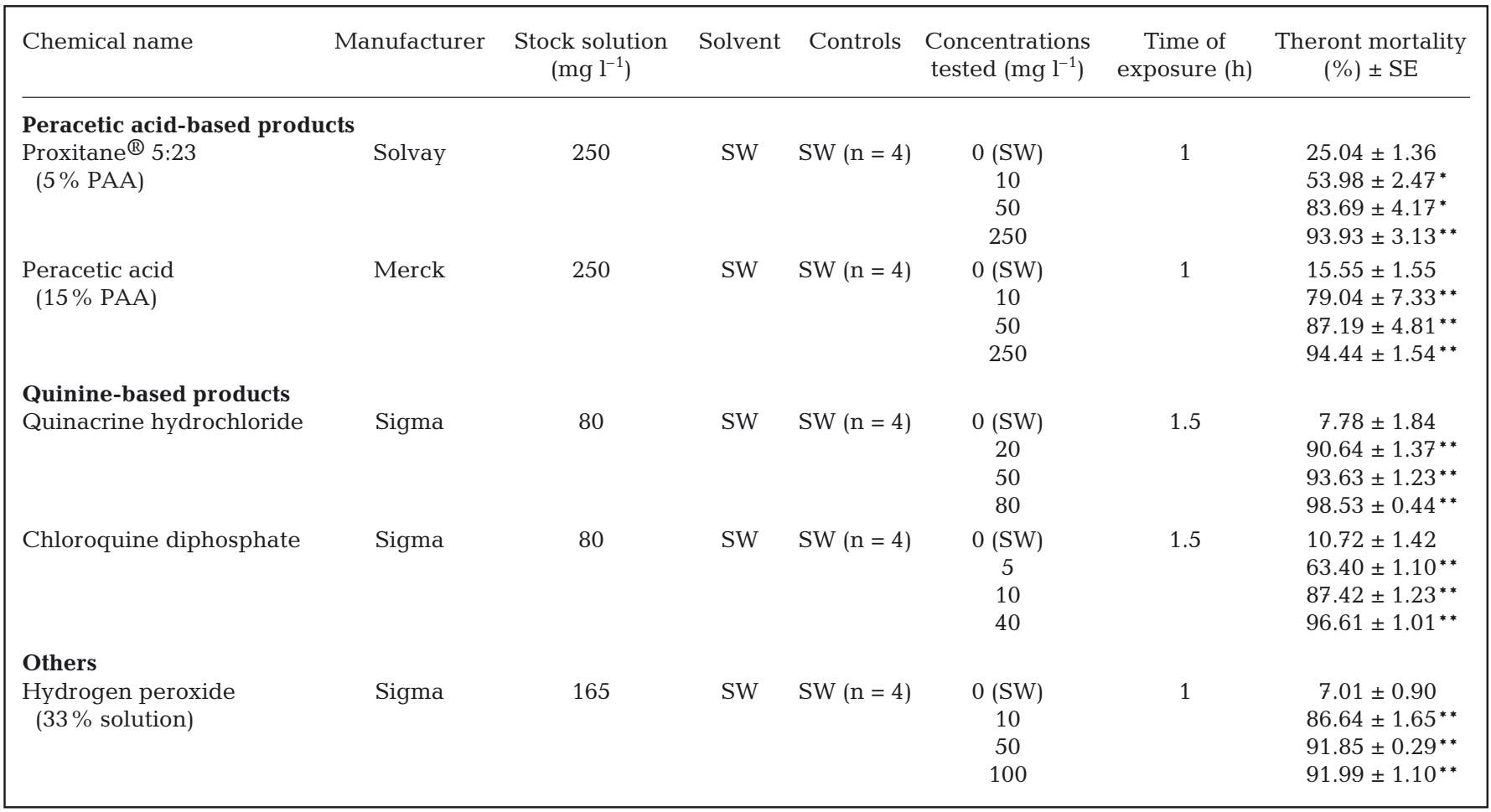

tive, with mortality rates of 80 and $87 \%$ respectively. The lowest concentration tested $\left(100 \mathrm{mg} \mathrm{l}^{-1}\right)$ also had a significant effect but achieved only $69 \%$ mortality. Papain caused low mortality rates after $3 \mathrm{~h}$ of treatment. When the period of exposure was increased to $6 \mathrm{~h}$, theront mortality rose to an average of $40 \%$ over all concentrations tested (Table 1). The differences in mortality rates when compared to the $C$. irritans freshwater counterpart, I. multifiliis, could be explained by the fact that whole-plant extract was used, instead of only papain, in addition to the use of sea water which might have affected the stability of the compounds when compared with freshwater, suggesting that it may be best applied as an in-feed treatments. Toxicity tests with extracts of $M$. pruriens have been carried out by Ekanem et al (2004); the results of these tests indicated that concentrations of 600 and $800 \mathrm{mg} \mathrm{l}^{-1}$ do not cause any mortality in Carassius auratus when this organism is exposed over a period of 96 h. C. auratus exposed to concentrations of 600 , 800 and $1000 \mathrm{mg} \mathrm{l}^{-1}$ of C. papaya extract for over $96 \mathrm{~h}$ did not show any signs of toxicity or stress (Ekanem et al 2004). Nevertheless, according to the results in the present study, higher concentrations are required to eliminate, or significantly decrease, the number of viable theronts.
Peracetic acid (PAA) has been used experimentally as an alternative compound for disinfection (Gustavino et al. 2005). The mode of action of PAA involves disruption of the transmembrane transporters in microorganisms. PAA-based compounds have been used successfully to control Saprolegnia parasitica Coker, 1923 infections in the eggs of rainbow trout Oncorhynchus mykiss (Meinelt et al. 2004). PAA, or combinations of PAA, hydrogen peroxide and acetic acid, have been proven to eliminate different life stages of Ichthyophthirius multifiliis (Meinelt et al. 2009, Straus \& Meinelt 2009, Sudová et al. 2010). In the current study, 2 different PAA-based compounds were tested: Proxitane ${ }^{\circledR}$ 5:23 (5\% PAA, $23 \%$ hydrogen peroxide, $10 \%$ acetic acid) and 15\% PAA (15\% PAA, 1 to $5 \%$ hydrogen peroxide, 50 to $75 \%$ acetic acid). Both of these PAA-based compounds showed high theront mortality rates after $1 \mathrm{~h}$ of exposure. The treatment with Proxitane ${ }^{\circledR}$ 5:23 for $1 \mathrm{~h}$ showed a moderate effect at a concentration of $10 \mathrm{mg} \mathrm{l}^{-1}$ with $54 \%$ theront mortality, whereas concentrations of 50 and $250 \mathrm{mg} \mathrm{l}^{-1}$ increased the theront mortality rate to 84 and $94 \%$ respectively. The exposure of theronts to $15 \%$ PAA for $1 \mathrm{~h}$ had a significant dose-dependent effect, with mortality rates ranging from 79 to $94 \%$ (Table 2). According to the results, the most cost-effective, and efficient, treatment is 
$10 \mathrm{mg} \mathrm{l}^{-1}$ of $15 \%$ PAA for $1 \mathrm{~h}$; this killed $\sim 80 \%$ theronts. The administration of PAA, however, has a limitation in that it degrades over time, in a temperature-dependent way, within the liquid phase (Zhao et al. 2008).

The 2 quinine-based compounds tested were quinacrine hydrochloride and chloroquine diphosphate. Both have been used extensively to treat different species of Plasmodium. Even if the antiprotozoal mechanism of quinacrine has not yet been fully elucidated, it is said to bind to DNA, thus stopping transcription/translation (Tracy \& Webster 1996). It also inhibits succinate oxidation, interferes with electron transport and acts as a strong inhibitor of cholinesterase (http://www.drugbank.ca/drugs/DB01103). In fish-parasitic protozoa, infeed treatments using flakes containing quinine appeared to alter the ultrastucture of the parasitic stages of Ichthyophthirius multifiliis in ornamental fish mainly by 'enlargement of the alveolar sacs, a partial destruction of the nephroplasm, and a sloughing off of the membranes bordering the contractile vacuoles' (Schmahl et al. 1996, p. 704). Quinacrine hydrochloride has been tested successfully in vitro against Tetrahymena pyriformis Ehrenberg, but appeared to be toxic to the fish. Quinine seems to affect cell division as well as mitochondrial activity (Griffin 1989). In vivo bath treatments with quinacrine hydrochloride were not able to reduce the number of trophonts of I. multifiliis on Oncorhynchus mykiss and caused $5 \%$ mortality (Tojo et al. 1994). However, other in-feed treatments managed to eradicate trophonts on fish fed with $5 \mathrm{~g}$ of quinine $\mathrm{kg}^{-1}$ feed for a minimum period of $7 \mathrm{~d}$ (Schmahl et al. 1996), and in vitro exposure of the marine protozoan Philasterides dicentrarchi to $100 \mathrm{mg}$ of quinine $\mathrm{l}^{-1}$ for $24 \mathrm{~h}$ killed the parasite efficiently (Iglesias et al. 2002). Chloroquine diphosphate has been proven to be efficient in killing $T$. pyriformis in vitro (Nilsson 1989). Nevertheless, in vivo trials using a bath and in-feed treatment were not effective in reducing the number of trophonts of I. multifiliis established in the challenged fish (Tojo et al. 1994). In the current study, after $1.5 \mathrm{~h}$ of treatment, quinacrine hydrochloride seemed to be the most effective of the 2 quinine treatments, with $~ 90 \%$ mortality among theronts in the 3 concentrations tested $\left(20,50\right.$ and $\left.80 \mathrm{mg} \mathrm{l}^{-1}\right)$. Cloroquine diphosphate caused $96 \%$ mortality after an exposure to $40 \mathrm{mg} \mathrm{l}^{-1}$ for $1.5 \mathrm{~h}$, followed by 10 and $5 \mathrm{mg} \mathrm{l}^{-1}$ with 87 and $63 \%$ mortality respectively (Table 2 ).

The bleaching agent hydrogen peroxide is a powerful oxidiser. In the treatment of the copepod Lepeophtheirus salmonis Krøyer, 1837 in Salmo salar L. cages, hydrogen peroxide was shown to cause the parasites to drop off, most likely through the production of lethal oxygen inside the parasite. The application of hydrogen peroxide is restricted owing to its toxic effect on treated fish (toxicity depending on water temperature) and the high volumes required to control infections in large aquaculture systems (Athanassopoulou et al. 2009). Concentrations of $100 \mathrm{mg} \mathrm{l}^{-1}$ over $1 \mathrm{~h}$ killed $\sim 20 \%$ of theronts of Ichthyophthirius multifiliis (A. S. Shinn unpubl.). However, daily treatments with $25 \mathrm{mg} \mathrm{l}^{-1}$ over $20 \mathrm{~d}$ did not control $I$. multifiliis infections and led to high mortalities in the treated fish (Tieman \& Goodwin 2001). In the current study, the 3 concentrations tested showed a theront mortality rate of $\sim 90 \%$ after $1 \mathrm{~h}$ of treatment (Table 2).

In conclusion, of the 8 different chemicals tested in vitro against the theront stage of $C$. irritans, 7 had an important effect on theront survival. However, further investigation involving in vivo trials is required to assess the potential of these chemicals in aquaria and aquaculture systems and to evaluate their effect on fish and invertebrates inhabiting the same system. Of the natural products, papain did not have a big impact on theront survival. In the light of the results obtained using Carica papaya extracts against Ichthyophthirius multifiliis, the use of crude extracts, instead of pure papain, to control Cryptocaryon irritans might be recommended. The use of L-DOPA and EGCG, considering their high market price, is restricted to aquaria or to the treatment of some valuable specimens. The most advisable administration of the 2 quinine-based compounds, quinacrine hydrochloride and cloroquine diphosphate, seems to be through bath treatments as precious studies against $I$. multifiliis showed palatability problems. From the results of the present study, the administration of Proxitane ${ }^{\circledR}$ 5:23 and 15\% PAA as bath treatments for $1 \mathrm{~h}$ seems to be the best approach for controlling $C$. irritans infections, as these compounds exhibit a very strong effect at low concentrations (such as $10 \mathrm{mg} \mathrm{l}^{-1}$ ).

In any case, the application of bath treatments will target only the free-living stages of the parasite (i.e. tomonts and theronts) because both the trophont and the encysted tomont are protected by the host's skin and the cyst wall, respectively. The life cycle of Cryptocaryon irritans follows circadian periodicity in which trophonts and theronts are released into the water column after dark (Yoshinaga \& Dickerson 1994, A. S. Holzer pers. comm.); this suggests that bath treatments should be carried out at night or just before sunrise to ensure maximum removal of parasites. Overall, both in-feed and bath treatment should be part of a continuous management programme which aims to maintain low infection levels in order to allow the fish to develop acquired immunity (Burgess 1992).

\section{LITERATURE CITED}

Ali M, Al-Olayan EM, Lewia S, Matthews H, Hurd H (2010) Naturally occurring triggers that induce apoptosis-like programmed cell death in Plasmodium berghei ookinetes. PLOS ONE 5:e12634 
Athanassopoulou F, Pappas IS, Bitchava K (2009) An overview of the treatments for parasitic disease in Mediterranean culture. Options Mediterr 86:65-83

Burgess PJ (1992) Cryptocaryon irritans Brown, 1951 (Ciliophora): transmission and immune response in the mullet Chelon labrosus (Risso, 1826). PhD thesis, University of Plymouth

Chu KB, Seng LT, Yong WS, Thye CT, Veloo P (2001) The life span of theront stages of Cryptocaryon irritans in different media, temperature and salinity. J Protozool Res 11:63-73

Colorni A (1985) Aspects of the biology of Cryptocaryon irritans, and hyposalinity as a control measure in cultured gilt-head sea bream Sparus aurata. Dis Aquat Org 1:19-22

Diggles BK, Adlard RD (1997) Intraspecific variation in Cryptocaryon irritans. J Eukaryot Microbiol 44:25-32

Duke JA (1981) Handbook of legumes of world economic importance. Plenum Press, New York, NY

- Ekanem AP, Obiekezie A, Kloas W, Knopf K (2004) Effects of crude extracts of Mucuna pruriens (Fabaceae) and Carica papaya (Caricaceae). Parasitol Res 92:361-366

García D, Escalante M, Delgado R, Ubeira FM, Leiro J (2003) Anthelminthic and antiallergic activities of Mangifera indica L. stem bark components Vimang and mangiferin. Phytother Res 17:1203-1208

Griffin BR (1989) Screening of chemicals to control protozoan parasites of fish. Prog Fish-Cult 51:127-132

Gustavino B, Buschini A, Monfrinotti M, Rizzoni M, Tancioni L, Poli P, Rossi C (2005) Modulating effects of humic acids on genotoxicity induced by water disinfectants in Cyprinus carpio. Mutat Res 587:103-113

- Hellmann JK, Münter S, Wink M, Frischknecht F (2010) Synergistic and additive effects of epigallocatechin gallate and digitonin on Plasmodium sporozite survival and motility. PLoS ONE 5:e8682

Hirazawa N, Oshima S, Hara T, Mitsuboshi T, Hata K (2001) Antiparasitic effect of medium-chain fatty acids against the ciliate Cryptocaryon irritans infestation in the red sea bream Pagrus major. Aquaculture 198:219-228

Hirazawa N, Goto T, Shirasu K (2003) Killing effect of various treatments on the monogenean Heterobothrium okamotoi eggs and oncomiracidia and the ciliate Cryptocaryon irritans cysts and theronts. Aquaculture 223:1-13

Iglesias R, Paramá A, Álvarez MF, Leiro J, Sanmartín ML (2002) Antiprotozoals effective in vitro against the scuticociliate fish pathogen Philasterides dicentrarchi. Dis Aquat Org 49:191-197

Leiro J, Arranz JA, Paramá A, Álvarez MF, Sanmartín ML (2004) In vitro effects of the polyphenols resveratrol, mangiferin and (-)-epigallocatechin-3-gallate on the scuticociliate fish pathogen Philasterides dicentrachi. Dis Aquat Org 59:171-174

Meinelt T, Phan TM, Stuber A, Bräunig I (2004) Wofasteril ${ }^{\circledR}$ und Wofasteril E250 zur Bekämpfung von Fischschimmelerste Erfahrungen. Fisch Teichwirt 11:888-890

Meinelt T, Matzke S, Stüber A, Pietrock M, Wienke A,

Editorial responsibility: Dieter Steinhagen,

Hannover, Germany
Mitchell AJ, Straus DL (2009) Toxicity of peracetic acid (PAA) to tomonts of Ichthyophthirius multifiliis. Dis Aquat Org 86:51-56

Nilsson JR (1989) Dose- and pH-dependent effects of chloroquine on Tetrahymena. Eur J Protistol 24:297-307

Park OJ, Surh Y (2004) Chemopreventive potential of epigallocatechin gallate and genistein: evidence from epidemiological and laboratory studies. Toxicol Lett 150:43-56

Raza H, John A (2008) In vitro effects of tea polyphenols on redox metabolism, oxidative stress and apostosis in PC12 cells. Ann N Y Acad Sci 1138:358-365

Schmahl G, Schmidt H, Ritter G (1996) The control of ichthyophthiriasis by a medicated food containing quinine: efficacy test and ultrastructure investigations. Parasitol Res 82:697-705

Straus DL, Meinelt T (2009) Acute toxicity of peracetic acid (PAA) formulations to Ichthyophthirius multifiliis theronts. Parasitol Res 104:1237-1241

Sudová E, Straus DL, Wienke A, Meinelt T (2010) Evaluation of continuous 4-day exposure to peracetic acid as a treatment for Ichthyophthirius multifiliis. Parasitol Res 106: $539-542$

Suzuki K, Misaka N, Sakai DK (2006) Efficacy of green tea extract on removal of the ectoparasitic flagellate Ichthyobodo necator from chum salmon, Oncorhynchus keta and masu salmon, O. masou. Aquaculture 259:17-27

> Tieman DM, Goodwin AE (2001) Treatments of Ich infestations in channel catfish evaluated under static and flowthrough water conditions. N Am J Aquaculture 63: 293-299

Tojo JL, Santamarina MT, Ubeira FM, Leiro J, Sanmartin ML (1994) Trials for the control of ichthyophthiriosis in rainbow trout (Oncorhynchus mykiss). Bull Eur Assoc Fish Pathol 14:148-152

Tona L, Kambu K, Ngimbi N, Cimanga K, Vlietinck AJ (1998) Antiamoebic and phytochemical screening of some Congolese medicinal plants. J Ethnopharmacol 61:57-65

Tracy JW, Webster LT (1996) Drugs used in the chemotherapy of protozoal infections. In: Hardman JG, Limbird LE (eds) The pharmacological basis of therapeutics. McGraw-Hill, New York, NY

Williamson MP, McCormick TG, Nance CL, Shearer WT (2006) Epigallocatechin gallate, the main polyphenol in green tea, binds to the T-cell receptor, CD4: potential for HIV-1 therapy. J Allergy Clin Immunol 118:1369-1374

Wright ADG, Colorni A (2002) Taxonomic re-assignment of Cryptocaryon irritans, a marine fish parasite. Eur J Protistol 37:375-378

Yoshinaga T, Dickerson HW (1994) Laboratory propagation of Cryptocaryon irritans on a saltwater-adapted poecilia hybrid, the black molly. J Aquat Anim Health 6: 197-201

Zhao X, Cheng K, Haob J, Liu D (2008) Preparation of peracetic acid from hydrogen peroxide, part II: kinetics for spontaneous decomposition of peracetic acid in the liquid phase. J Mol Catal Chem 284:58-68

Submitted: May 31, 2010; Accepted: November 24, 2010 Proofs received from author(s): March 1, 2011 